\title{
Miscibility of Poly(vinylidene fluoride) and Poly(styrene-co-methyl methacrylate) Blends
}

\author{
Won Ho Jo, Jong Tae Yoon, and Sang Cheol LeE* \\ Department of Textile Engineering, Seoul National University, Seoui 151-742, Korea \\ *Department of Polymer Science and Engineering, Kum-Oh Institute of Technology, \\ Kumi City, Kyungbuk 641, Korea
}

(Received January 17, 1991)

\begin{abstract}
The miscibility of poly(vinylidene fluoride) (PVDF) and poly(styrene-co-methyl methacrylate) (SMMA) blends was examined as a function of copolymer composition. PVDF was miscible with SMMA copolymers having an styrene content less than $13 \mathrm{vol} \%$. The segmental interaction parameters were determined by combining the equilibrium melting point depression of PVDF and the binary interaction model. According to the binary interaction model, the maximum styrene content in SMMA for the blend to be miscible was predicted as $18.5 \mathrm{vol} \%$ which agrees well with an experimental result.
\end{abstract}

KEY WORDS Miscibility / Binary Interaction Model / Poly(vinylidene fluoride) / Poly(styrene-co-methyl methacrylate) / Melting Poing Depression / Segmental Interaction Parameter/

Recently, many studies $^{1-12}$ have been carried out on the miscibility of polymer blends containing a copolymer, because miscibility can be attained for a certain range of copolymer composition even though the pairs of their corresponding homopolymers are immiscible. This phenomenon has been successfully understood based on the binary interaction model proposed by Kambour et al. ${ }^{1}$ In this model, a thermodynamic interaction parameter between a polymer pair is governed by the interaction parameters between the segmental pairs with different chemical structure. More recently, Paul et al., ${ }^{2-6}$ Karasz et al. ${ }^{7,8}$ and others $^{9-12}$ have further extended the above binary interaction model to several types of blends containing copolymers and applied the model to interpret the effect of copolymer composition on the miscibility of blends.

Blends of poly(vinylidene fluoride) (PVDF) and poly(methyl methacrylate) (PMMA) have been studied extensively and reported to be miscible, ${ }^{13-17}$ while blends of PVDF and polystyrene (PS) is a well-known immiscible pair. In this study, the miscibility for blends of PVDF and poly(styrene-co-methyl methacrylate) (SMMA) was examined as a function of copolymer composition and interpreted in terms of the segmental interaction parameters, which are determined by combining the binary interaction model with the data obtained from the equilibrium melting point depression. It is also attempted to predict the critical copolymer composition for the blends to be miscible using the calculated segmental interaction parameters and the binary interaction model.

\section{EXPERIMENTAL}

\section{Materials}

PVDF $\left(M_{w}=1.0 \times 10^{5} \mathrm{~g} / \mathrm{mol}\right)$ and PMMA $\left(M_{w}=1.5 \times 10^{5} \mathrm{~g} \mathrm{~mol}^{-1}\right)$ were obtained from Pennwalt Co. and Lucky Inc. respectively and used as received without further purification. SMMA was synthesized by bulk polymerization in a sealed glass ampule using benzoyl 
peroxide as an initiator at $60^{\circ} \mathrm{C}$. The copolymer was purified by pouring the reaction mixture into methanol and dried in a vacuum oven at $100^{\circ} \mathrm{C}$ for $24 \mathrm{~h}$. The methyl methacrylate content in the copolymer was determined by the elemental analysis based upon the weight of carbon atom. The copolymer composition and glass transition temperature are listed in

Table I. Properties of SMMA copolymers

\begin{tabular}{|c|c|c|c|}
\hline Sample & $\begin{array}{l}\text { Copolymer } \\
\text { composition }\end{array}$ & $\begin{array}{l}\text { Intrinsic } \\
\text { viscosity }\end{array}$ & $T_{\mathrm{g}}$ \\
\hline & vol\% of styrene & $\mathrm{dl} \mathrm{g}^{-1}$ & ${ }^{\circ} \mathrm{C}$ \\
\hline SMMA2 & 1.9 & 1.24 & 127 \\
\hline SMMA9 & 8.9 & 1.08 & 122 \\
\hline SMMA13 & 13.6 & 1.15 & 121 \\
\hline SMMA24 & 24.0 & 1.10 & 117 \\
\hline
\end{tabular}
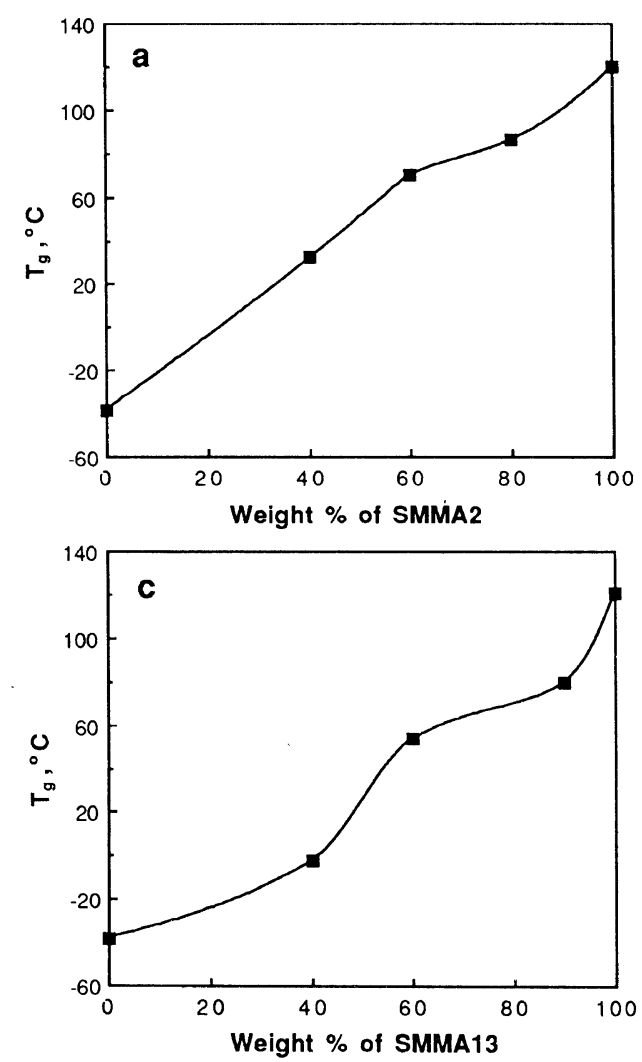

Table I.

\section{Preparation of Blends}

The blends of PVDF/SMMA were prepared by dissolving the component polymers in $N, N^{\prime}$-dimethylformamide. The solutions were cast on aluminum dish and dried in a vacuum oven $60^{\circ} \mathrm{C}$ for $72 \mathrm{~h}$.

\section{Thermal Analysis}

Thermal analysis was perfomed on a Du Pont 910 differential scanning calorimeter equipped with a mechanical cooling accessory. For the measurement of glass transition temperature $\left(T_{\mathrm{g}}\right)$, the sample were melted at $200^{\circ} \mathrm{C}$ for $5 \mathrm{~min}$, quenched into liquid nitrogen to prevent the crystallization of PVDF, and heated from $-70^{\circ} \mathrm{C}$ to $150^{\circ} \mathrm{C}$ at a heating rate of $20^{\circ} \mathrm{C} \mathrm{min}^{-1}$. The glass transition tempera-
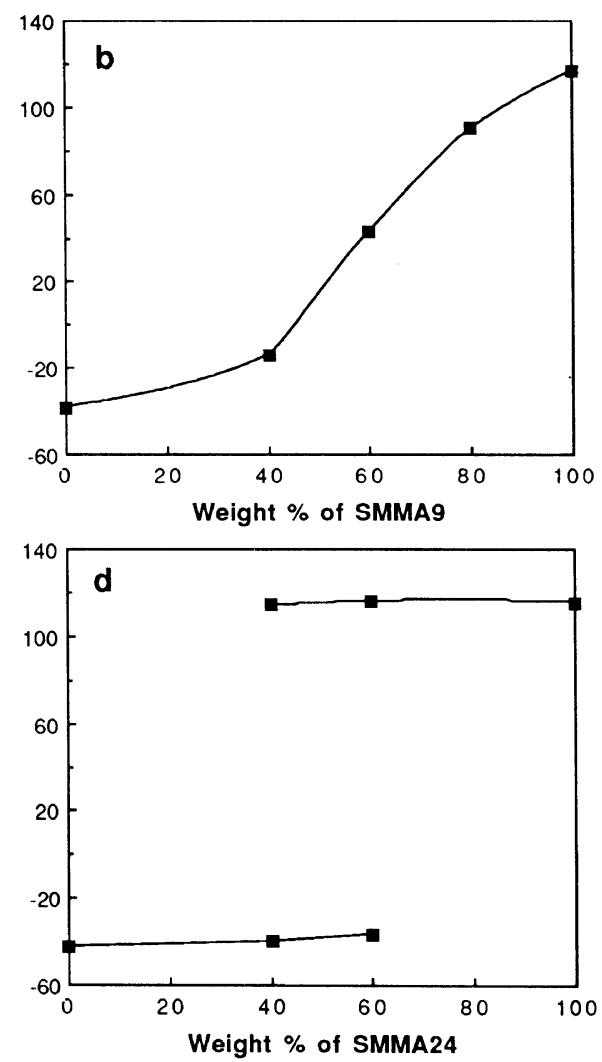

Figure 1. Glass transition behaviors for (a) PVDF/SMMA2, (b) PVDF/SMMA9, (c) PVDF/SMMA13, and (d) PVDF/SMMA24 blends. 
ture was taken as the midpoint of the heat capacity change. The isothermal crystallization from the melt was also carried out to determine the equilibrium melting temperature. The samples were melted at $200^{\circ} \mathrm{C}$ for $5 \mathrm{~min}$, cooled quickly to the crystallization temperature $\left(T_{\mathrm{c}}\right)$, and kept at $T_{\mathrm{c}}$ for at least $20 \mathrm{~min}$. After isothermal crystallization was terminated, the samples were cooled to room temperature, and then heated to $200^{\circ} \mathrm{C}$ at a heating rate of $20^{\circ} \mathrm{C}$ $\min ^{-1}$ for measuring the melting temperature $\left(T_{\mathrm{m}}\right)$.

\section{RESULTS AND DISCUSSION}

The existence of a single and composition dependent glass transition temperature between those of pure components is a widely used criterion in determining the miscibility of a polymer blend. Figure 1 shows that blends of PVDF/SMMA2, PVDF/SMMA9 and PVDF/SMMA13 have a single glass transition temperature between those of components, indicating that mixtures are completely miscible over the entire blend ratio. However, PVDF/SMMA24 blend shows two glass transition temperatures located at nearly the same temperatures as those of component polymers, indicating that the blend is immiscible.

In order to obtain quantitative information about the thermodynamic interactions in the blends, we used the Nishi-Wang equation: ${ }^{18}$

$$
T_{\mathrm{m}}^{0}-T_{\mathrm{m}}=-T_{\mathrm{m}}^{0} \frac{B V_{2 \mathrm{u}}}{\Delta H_{2 \mathrm{u}}} \phi_{1}^{2}
$$

where $\Delta H_{2 \mathrm{u}} / V_{2 \mathrm{u}}$ means the latent heat of fusion of pure crystalline component per unit volume, $B$ is the interaction parameter between blend components, $\phi_{1}$ is the volume fraction of the amorphous component and $T_{\mathrm{m}}^{0}$ and $T_{\mathrm{m}}$ are melting temperature of the pure crystallizable polymer and of the blend, respectively. However as Morra and Stein ${ }^{17}$ have pointed out, the directly measured melting points are not equilibrium values since they have a
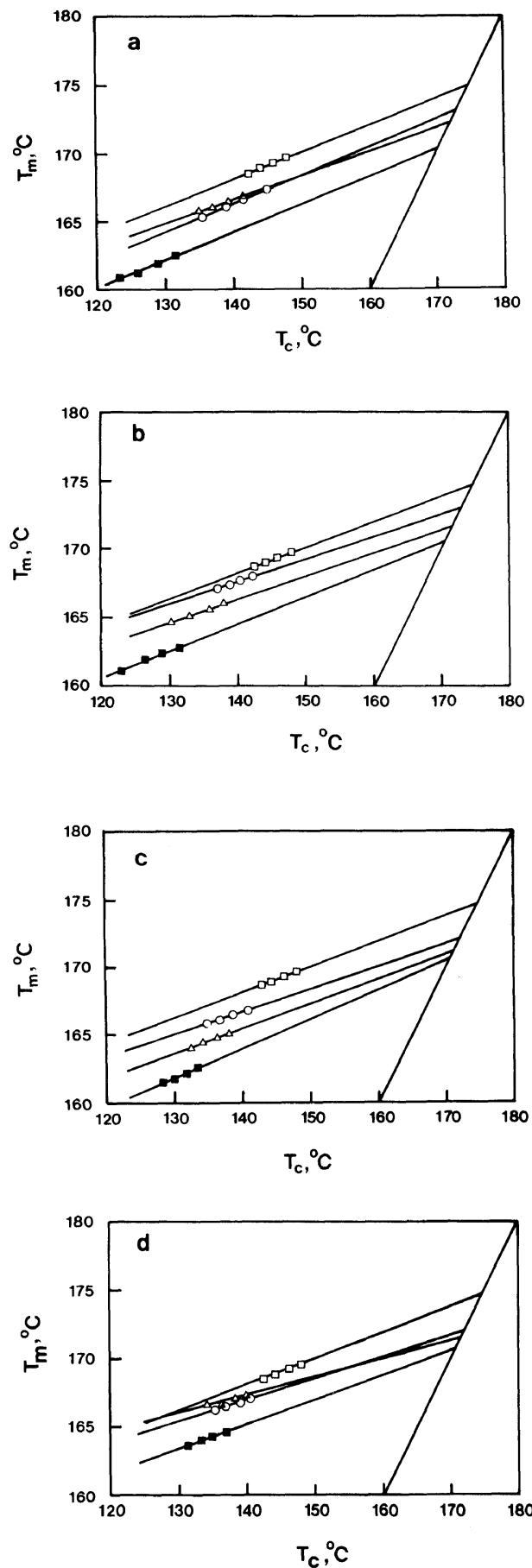

Figure 2. Hoffman-Weeks plots for (a) PVDF/PMMA, (b) PVDF/SMMA2, (c) PVDF/SMMA9, and (d) PVDF/ SMMA13 blends: $(\square)$ 100; $(\bigcirc)$ 90; $(\triangle)$ 80; (ロ $70 \mathrm{wt} \%$ PVDF. 

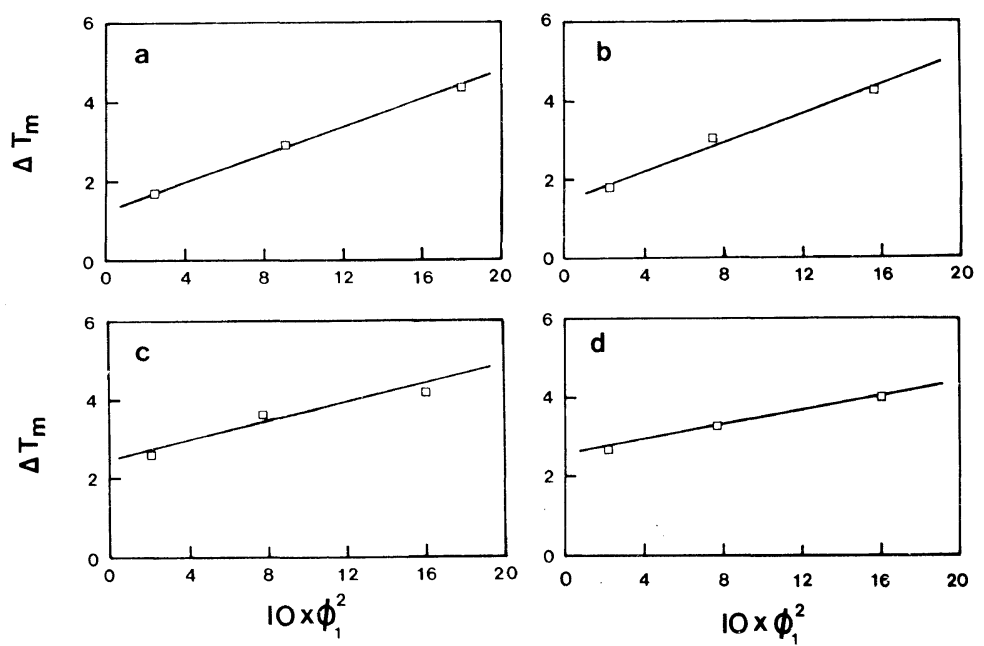

Figure 3. Plots of $\Delta T_{m}$ versus $\phi_{1}^{2}$ for (a) PVDF/PMMA, (b) PVDF/SMMA2, (c) PVDF/SMMA9, and (d) PVDF/SMMA13 blends.

contribution from finite lamellar thickness. To eliminate the effect of finite lamellar thickness from the melting temperature, the method of Hoffman-Weeks ${ }^{19}$ has been used and the equilibrium melting temperatures for pure PVDF and blends of given compositions were determined. Figure 2 represents the HoffmanWeeks plots to obtain the equilibirium melting temperatures for pure PVDF and $\mathrm{PVDF} /$ SMMA blends.

The interation parameter between both components $B$ can be easily derived from eq 1 if one knows the equiliberium melting point depression for a give composition. The weight fractions were converted into volume fractions using the molar volumes of monomeric units determined by group contribution method. ${ }^{20}$ By using the data of $V_{2 \mathrm{u}}=36.4 \mathrm{~cm}^{3} \mathrm{~mol}^{-1}$ and $\Delta H_{2 \mathrm{u}}=1,600 \mathrm{cal} \mathrm{mol}^{-1},{ }^{21} \mathrm{~B}$ values were calculated from the slopes of Figure 3. The results are listed in Table II. Negative $B^{\prime}$ s for PVDF/ PMMA, PVDF/SMMA2, PVDF/SMMA9 and PVDF/SMMA13 support the fact that these systems are miscible. It is also found that $B$ value decreases as the styrene content in SMMA increases. This indicates that the styrene unit in SMMA plays an unfavorable role for the miscibility of PVDF/SMMA
Table II. Interaction parameters for the miscible blends

\begin{tabular}{lc}
\hline \multicolumn{1}{c}{ Blend Pair } & $B / \mathrm{cal} \mathrm{cm}^{-3}$ \\
\hline PVDF/PMMA & -1.72 \\
PVDF/SMMA2 & -1.69 \\
PVDF/SMMA9 & -1.11 \\
PVDF/SMMA13 & -0.91 \\
\hline
\end{tabular}

blends.

In mixture of a homopolymer $\mathrm{A}$ and a random copolymer $C_{y} D_{1-y}$, the interaction parameter $B$ can be expressed as eq. $2:^{2}$

$$
B=y B_{\mathrm{AC}}+(1-y) B_{\mathrm{AD}}-y(1-y) B_{\mathrm{CD}}
$$

where $B_{i j}$ is the segmental interaction parameter and $y$ is the volume fraction of $\mathrm{C}$ units in the copolymer. This equation represents that the overall interaction parameter $B$ can be expressed in terms of the segmental interaction parameter $B_{i j}^{\prime} \mathrm{s}$ and the copolymer composition.

To apply eq 2 to PVDF/SMMA blends, we let vinylidene flouride $=\mathrm{A}$, styrene $=\mathrm{C}$ and methyl methacrylate $=\mathrm{D}$. The segmental interaction parameter $B_{i j}^{\prime} \mathrm{s}$ were calculated from the nonliner regression of eq 2 , using the four $B$ values (see Table II) for four PVDF/SMMA 


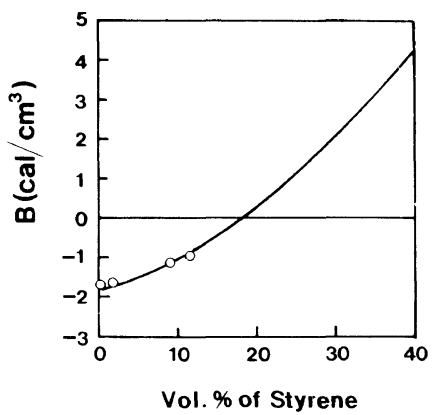

Figure 4. The dependence of interaction parameter $B$ on the copolymer composition. Circles are experimental values and the solid line was computed from eq 2 by using $B_{\mathrm{AD}}, B_{\mathrm{AC}}$ and $B_{\mathrm{CD}}$.

blend differing in SMMA composition $y$ :

$$
\begin{aligned}
B_{\mathrm{AD}} & =-1.87 \mathrm{cal} \mathrm{cm}^{-3} \\
B_{\mathrm{AC}} & =28.42 \mathrm{cal} \mathrm{cm}^{-3} \\
B_{\mathrm{CD}} & =24.72 \mathrm{cal} \mathrm{cm}^{-3}
\end{aligned}
$$

The negative values $\left(-1.87 \mathrm{cal} \mathrm{cm}^{-3}\right)$ of $B_{\mathrm{AD}}$ means that PMMA is miscible with PMDF and this value is comparable with the reported value $\left(-2.98 \mathrm{cal} \mathrm{cm}^{-3}\right) .{ }^{22}$ The positive values of $B_{\mathrm{AC}}$ and $B_{\mathrm{CD}}$ imply that PS/PMMA and PVDF/PS blends are immiscible. The signs of $B_{i j}$ values are reasonable, recalling the miscibility for the corresponding homopolymer pairs. However, the absolute magnitudes of these values are somewhat large in a practical sence. This may be caused by many assumptions included in theories for the calculation of $B_{i j}$ values.

The binary interaction model (eq 2) can predict the maximum styrene content $y_{\max }$ in the SMMA copolymer where the heat of mixing of the blend is zero. Equation 2 can be solved for $y$ after letting the overall $B$ value be zero, and inserting calculated segmental $B_{i j}$ values. The calculated $y$ value is approximately $18.5 \mathrm{vol} \%$. This value agrees well with an experimental result that PVDF/SMMA24 blend shows double glass transition temperatures, indicating the blend is immiscible. The dependence of overall $B$ values on the copolymer composition is shown in Figure 4 where the solid line was computed from eq 2 by using the three calculated $B_{i j}$ values.

\section{REFERENCES}

1. R. P. Kambour, J. T. Bendler, and R. C. Bopp, Macromolecules, 16, 753 (1983).

2. D. R. Paul and J. W. Barlow, Polymer, 25, 487 (1984).

3. E. M. Woo, J. W. Barlow, and D. R. Paul, Polymer, 26, 763 (1985).

4. A. C. Fernandes, J. W. Barlow, and D. R. Paul, J. Appl. Polym. Sci., 32, 5357 (1986).

5. M. E. Fowler, J. W. Barlow, and D. R. Paul, Polymer, 28, 1177 (1987).

6. K. E. Min and D. R. Paul, J. Polym. Sci., Polym. Phys. Ed., 26, 2257 (1988).

7. G. ten Brinke, F. E. Karaz, and W. J. MacKnight, Macromolecules, 16, 1827 (1983).

8. T. Shiomi, F. E. Karasz, and W. J. MacKnight, Macromolecules, 19, 2274 (1986).

9. M. Suess, J. Kressler, and H. W. Kammer, Polymer, 28, 957 (1987).

10. J. Kressier, H. W. Kammer, G. Schmidt-Noake, and K. Herzoy, Polymer, 29, 686 (1988).

11. Y. Y. Chien, E. M. Pearce, and T. K. Kwei, Macromolecules, 21, 1616 (1988).

12. W. H. Jo and S. C. Lee, Macromolecules, 23, 2261 (1990).

13. T. T. Wang and T. Nishi, Macromolecules, 10, 421 (1977).

14. D. J. Houston and I. D. Hughers, Polymer, 18, 1195 (1977).

15. E. Roerdink and G. Challa, Polymer, 19, 173 (1978).

16. J. Mijovic, H. L. Luo, and C. D. Han, Polym. Eng. Sci., 22, 234 (1982).

17. B. Morra and R. S. Stein, J. Polym. Sci., Phys. Ed., 20, 2243 (1982).

18. T. Nishi and T. T. Wang, Macromolecules, 8, 809 (1975).

19. J. D. Hoffman and J. J. Weeks, J. Chem. Phys., 42, 4301 (1965).

20. D. W. van Krevelen, "Properties of Polymers," Elsevier Scientific, Amsterdam, 1976, Chapter 4.

21. K. Nakagawa and Y. Ishida, J. Polym. Sci., Polym. Phys. Ed., 11, 2153 (1973).

22. T. K. Kwei and T. T. Wang, Macromolecules, 8, 909 (1975). 